\title{
IDEAH
}

\section{Intellectual Development and Management of Collaborative Research Projects in the Digital Humanities}

\section{Harold Short ${ }^{1}$}

${ }^{1}$ King's College London

Published on: Jan 27, 2022

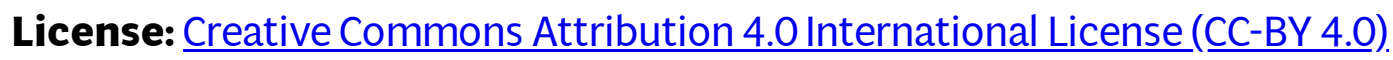


This paper gives greater emphasis to the intellectual challenges in large-scale collaborative research projects in the digital humanities than to some of the more practical aspects, such as specific project management techniques, crucially important though these are.

Section 1, the Introduction, begins with a brief outline of the stages in intellectual development which are discussed in greater detail in the main body of the paper. This is followed by a brief overview of four case study projects that are used to illustrate the discussion, along with contextual material on contemporary and current projects.

Section 2 provides a brief description of each of the four case study projects, providing a general overview of each, and highlighting particular aspects that are relevant to the later discussion. This means the four descriptions are different in structure, but there would not be space in this paper to provide an exhaustive description of each. Each project resulted in a substantial online publication, which can be accessed for more details if this is of interest.

Section 3 outlines and discusses the wider collaborative domain in which such projects are developed and addresses the role of 'digital humanities specialists'. Section 4 provides the heart of the paper, with seven sub-sections, each addressing one of the suggested stages in the intellectual development of collaborative projects. Finally, section 5 offers some concluding thoughts, plus a checklist of the six phases discussed, for ease of reference.

\section{Section 1. Introduction}

To aid in the discussion of the project development process, I have broken it into six phases and used examples from four case studies. Collaborative research requires at the outset a process of expressing and agreeing common goals. The key to this is the clear identification of source materials and/or theoretical challenges, and careful articulation of the range of research questions to be pursued and the contributions that will be required from each group of participants. There follows a process of mutual education so as to align methods and ways of working, beginning with the methods familiar to each group of collaborators, but often requiring the mutual exploration and development of new or extended methods.

The project team needs, of course, to agree on the practical aspects of project management, and to establish clear procedures and guidelines, but even with these 
things in place there are likely to be continuing intellectual challenges as the project is developed and as it proceeds. From the beginning there will be areas of "contest", often across discipline boundaries, but even within a discipline. These are especially likely where a discipline's 'traditional' methods have not required highly specified and narrowly defined categorisations. The quality of the initial intellectual work and then the ways in which challenges are managed and resolved will determine to a large extent the success of the project in meeting the agreed objectives.

\section{Case studies: overview}

This paper draws for examples and illustrations on a set of case studies, all projects in which the author was involved as Technical Research Director while at King's College London during the period 1995-2010. 1 To provide background and context, brief descriptions follow. It is worth emphasizing that these are only four of over 50 collaborative projects at King's in that period. By now, of course, there are hundreds if not thousands of digital humanities projects world-wide.

These four case studies are included here not as models of perfection-as will become clear-but because they illustrate in their different ways the arguments I'm presenting, and because I can speak from direct experience. Although by no means perfect, each was nevertheless judged to be very successful, by the principals, advisory boards, funding bodies and externally in various types of peer review. All produced substantial online publications that are still in wide use and regarded as important resources in the relevant discipline areas.

\section{Passage of Time}

An obvious question is what relevance four now rather old projects have to current collaborative research in digital humanities. My hope is that the passage of time provides for mature reflection on my part; at the same time the principles that guided the development and management of these projects, drawn as they were not only from our own experience at King's but also from that of other major projects in the field, remain as valid today as they were then, and are used by many successful collaborative projects. I hope, therefore, that a re-articulation will serve a useful purpose, and will offer ideas and insights to those planning collaborative projects today.

\section{Contemporary Exemplars and Context}

The University of Virginia's Institute for Advanced Technology in the Humanities (IATH), directed at the time by John Unsworth, was a major inspiration for our 
projects. At the Digital Resources in the Humanities conference at Oxford in 1997, Unsworth chaired a panel entitled "Creating Digital Resources: The Work of Many Hands", which illustrated and emphasized the scholarly potential—and challenges—of large-scale collaborations. The other panellists included the lead scholars in several of IATH's major collaborations, including the Blake Archive, the Emily Dickinson Archive and the Walt Whitman Archive. Two other IATH projects of major importance to us as models were the Rossetti Archive and the Valley Project. The first three of these are no longer hosted at the University of Virginia, but all five remain live online publications, of major importance to their scholarly communities. $\underline{2}$

There were also a number of European institutions and projects that offered ideas and guidance, including those in Oxford (in England), Pisa and Rome, Bergen (Norway), and several German institutions, in particular perhaps Tübingen and Göttingen, where Manfred Thaller was at the time.

\section{Large-scale infrastructure projects}

In addition to an ever-growing number and variety of collaborative research projects, very large-scale infrastructure initiatives have been proliferating over recent years. In Europe, Digital Research Infrastructure for Language Resources and Technology (DARIAH), Common Language Resources and Technology Infrastructure (CLARIN), and now the Common Lab Research Infrastructure for the Arts and Humanities (LARIAH), come immediately to mind. Australia has Humanities Networked Infrastructure (HuNI); and there are many others. Undoubtedly the most wide-ranging and ambitious international project in the (digital) humanities was/is the Text Encoding Initiative (TEI), which ran as a funded project from 1987 to 1999, and involved hundreds of scholars from many different (text-oriented) disciplines and subdisciplines around the world. Since 2000 the TEI Consortium has continued the work of providing a forum for scholarly discussion and definition of standards around the exchange, re-use and re-purposing of text-based research. $\underline{3}$

A more recent initiative not far behind the TEI in its scope and ambition is the Implementing New Knowledge Environments (INKE) project, which has already developed a substantial body of published work, and hosts a continuing series of international symposia and workshops exploring ideas of open scholarship. Although the scale of such a project is well beyond the needs or ambitions of the kind of research described in this paper, the project nevertheless has a great deal to offer as a model to smaller projects in relation to establishing collaborative relationships (a 6year process in their case!), and preparing, establishing and managing the projects. 
The INKE experience is described in helpful detail in "Interface/Interaction and the Book: A Consultation-Derived Perspective on Foundational E-Book Research" by Ray Siemens et al. 178-181.

For this paper, however, we will focus on collaborative research at a less massive scale, of the kind likely to involve the creation of a scholarly archive or preparation of a digital edition.

\section{Section 2: Case Studies}

The "Projects Cited" section at the end of this paper provide the names of the principal investigators (PI) for each project. Further information can be found on the project websites. When these projects were in development, the technical research partner was called the Centre for Computing in the Humanities. It became an academic department in 2002 and in 2011 it changed its name to the Department of Digital Humanities (DDH). It can be found at www.kcl.ac.uk/ddh.

\section{Prosopography of Anglo-Saxon England (PASE)}

For those who might be unfamiliar with the term, prosopography is a sub-discipline of history that seeks to collect and analyse evidence in a systematic way about some defined group of individuals, with a view to understanding their society. It is sometimes also described as 'collective biography'. $\underline{4}$ The aim in PASE was "to provide structured information relating to all the recorded inhabitants of England from the late sixth to the late eleventh century" (PASE, "Home").

The research team collected information about these persons from modern scholarly editions of all the available written sources, "including chronicles, saints' Lives, charters, libri vitae, inscriptions, Domesday Book and coins" (PASE, "Home"). $\underline{5}$ The key goals of the project, therefore, were to provide source-based evidence about individuals and groups for researchers interested in any aspect of Anglo-Saxon lives and society. Janet L Nelson, the project's Principal Investigator, discusses this in further detail in "From Building Site to Building" (Nelson 123-125).

\section{Clergy of the Church of England Database (CCEDB)}

The Church of England was established when King Henry VIII broke from the Roman Catholic Church in 1533 (the English Reformation). From that time it has been the 'established' state church, and consequently an important part of England's institutional and social fabric. From the early nineteenth century records of clerical ordinations and appointments were centrally collected and are available for research, 
but such records as exist for the period prior to this are scattered in over 50 archives around England and Wales.

The project aimed to collect and integrate the available information from these disparate archives in as systematic a way as possible, making it available for search and analysis, thereby providing a substantial body of source-based evidence for researchers interested not only in the history of the Church of England but also more generally in the social and political history of England and Wales from the Reformation to the early $19^{\text {th }}$ Century.

\section{Fine Rolls of Henry III 1216-1272 (FRH3)}

At the time of the English King Henry III's reign (1216-1272), a fine "was essentially a promise of money to the king in return for a concession or favour" (FRH3, "The Nature of the fine rolls"). It was one of the most important means by which Henry raised revenue. During the reign of Henry's predecessor, King John (1199-1216), the chancery began to keep records of court transactions in a highly systematic way, a process that continued through succeeding reigns. The transactions were recorded on manuscripts that were then sewn together so they could be rolled up, one roll per year. As a result, there is a Fine roll for each year of Henry's reign, held in the United Kingdom's National Archives. A major goal of the project was to make the information in the rolls available to scholars and the wider community, filling a major lacuna since there had never been a complete printed edition.

For political historians this reign is important in part because of Magna Carta-the Great Charter-which was sealed under duress by King John in 1215, but then renounced at the end of his reign. It was reinstated at the start of Henry's reign in 1216, and finally reaffirmed in 1225. It has been of central importance in English political and constitutional history ever since. As the project website explains, "If Henry's long reign can be said to have one overriding theme, it is the story of how a king and his subjects came to terms with Magna Carta." (FRH3, "The Minority of Henry III and its aftermath, 1216-1234"). The fine rolls offer "the earliest systematic evidence of what people and institutions across society wanted from the king and he was prepared to give" (FRH3, "Between Magna Carta and the Parliamentary State"), and for this reason is of crucial importance to historians of the period, whether political, social or economic.

The main aim of the project was to make the fine rolls available both in their original Latin (via high-quality digital facsimiles), and in translation, with mechanisms for free- 
text and structured searches, thereby providing a substantial body of source-based evidence for the use of historians and others interested in this period of English history and in the development of the English parliamentary state. $\underline{6}$

\section{Inscriptions of Aphrodisias (IAph)}

For the purposes of this paper, my focus is not as much on the inscriptions themselves, important though these are, but with way in which the project became the catalyst, by design, for wide international engagement with researchers interested in the scholarship of small chunks of text, in all forms and from all periods.. As a result, one of its principal legacies is a series of subsequent projects that have adopted the same or similar methods. $\underline{7}$

Charlotte Roueché's monograph Aphrodisias in Late Antiquity, was based on extensive archaeological work at the site of Aphrodisias in what is modern day Turkey, specifically the recording, measurement and research on inscriptions that were found there. $\underline{8}$, $\underline{9}$ The 1989 publication included some 200 inscriptions, and when it went out of print, Roueché approached colleagues in DDH about the possibility of preparing a revised electronic edition. The development and publication of this electronic edition (Roueché, Aphrodisias in Late Antiquity) formed the basis of the IAph project, whose purpose was to publish a more complete collection of the inscriptions than had appeared in the earlier publication. $\frac{10}{}$ A key part of the earlier project was collaboration with Tom Elliott and Hugh Cayless, then at the University of North Carolina Chapel Hill, whom Roueché had already been consulting. They were developing a TEI standard for epigraphy known as EPIDOC. 11 This formed the basis of the first project and became the underlying technical platform for IAph-and a great many subsequent projects world-wide.

In the funding bid, finance was specifically requested for three workshops each year, one in North America, one in the UK and one in mainland Europe. The purpose of the workshops was to bring together as many scholars as possible to discuss common problems and to test the idea of collaborating in the use of a common underlying technical standard. In the event, by taking advantage of relevant conferences, colloquia and other meetings, it proved possible to hold a dozen or more of these workshops over the three years of the funded project.

\section{Section 3: The Collaborative Domain}




\section{DH as a Space for Collaborative Engagement}

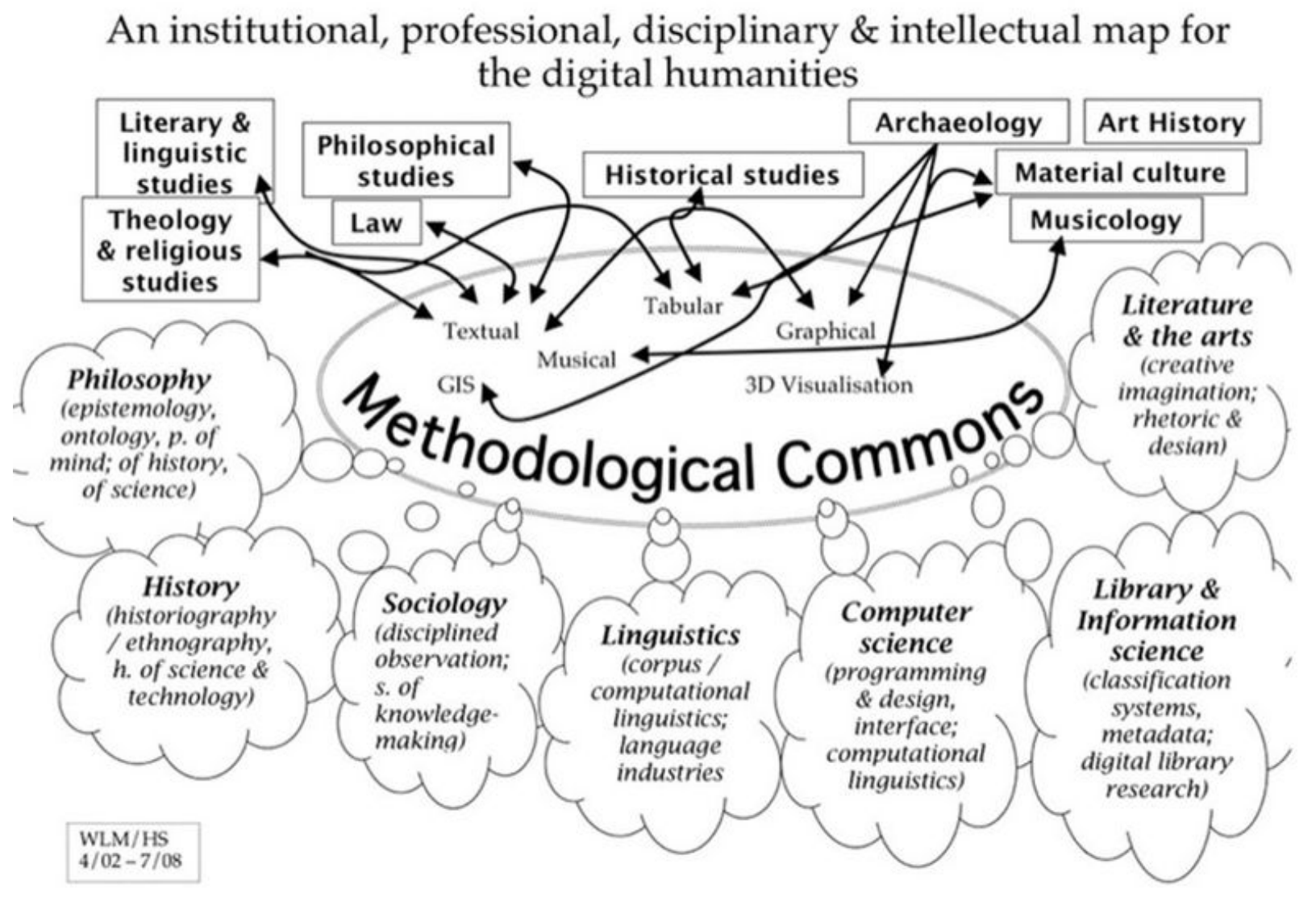

Figure 1 : McCarty \& Short: Digital Humanities and the Methodological Commons

Figure 1 is a variation on a diagram which Willard McCarty and I first developed for a small colloquium hosted in 2001 in Pisa by the late Antonio Zampolli, on the theme "a humanities computing roadmap". $\underline{12}$ The diagram has been through a number of modifications over the years, various formats appearing online, and one version appearing in print (McCarty, Humanities Computing 119). The diagram describes a collaborative space between disciplines, with the emphasis being first the common applicability of technical methods across many different arts and humanities disciplines, and second, the innovation or transformation of method that typically arises from intellectual work in this space-hence the designation of the space as a "methodological commons". McCarty's own discussion of the diagram is to be found in McCarty, Humanities Computing $118 \mathrm{ff}$. 


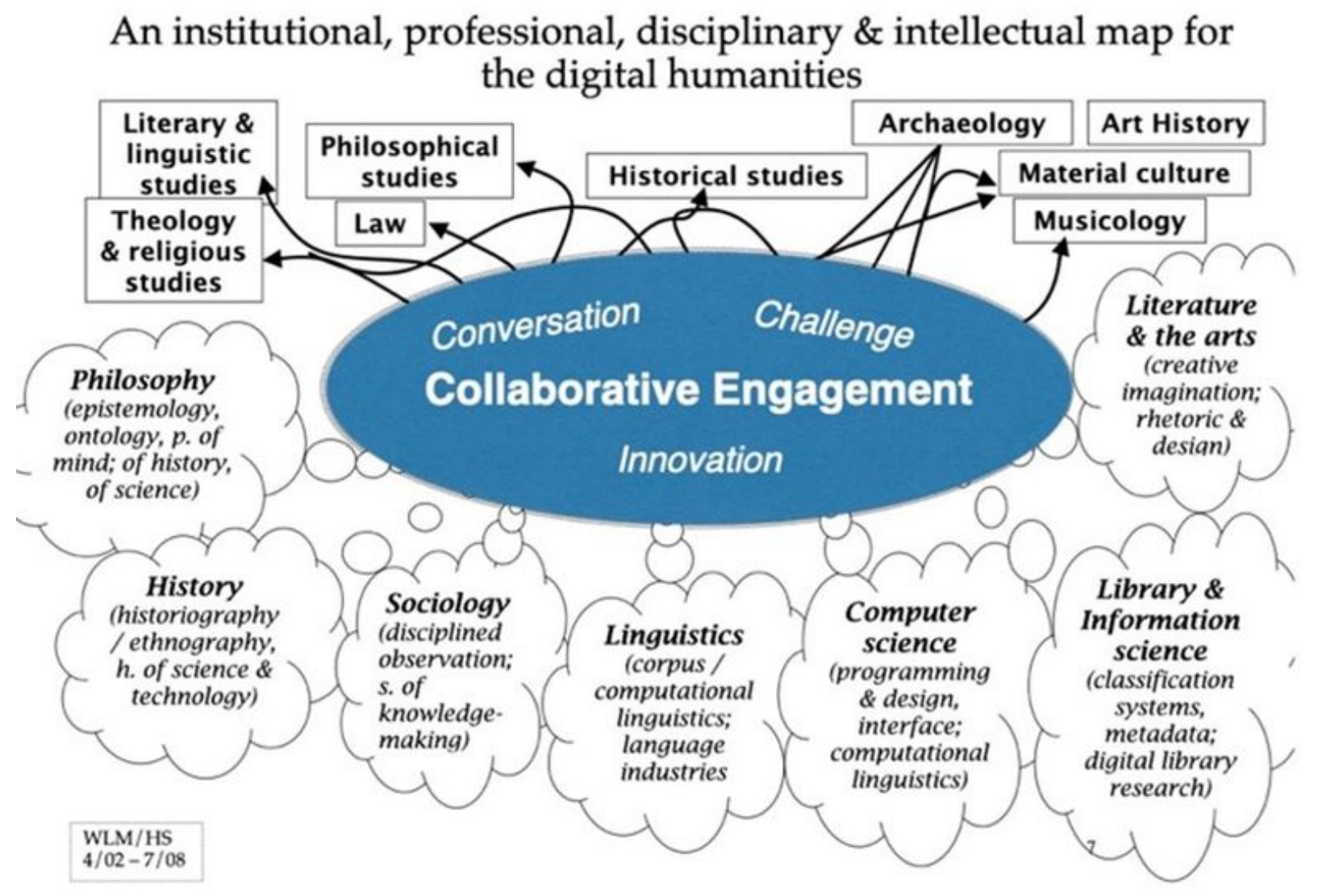

Figure 2: Short after McCarty \& Short: Digital Humanities as a space for Collaborative Engagement.

More recently, I created an overlay, as shown in Figure 2, which emphasises the significance of this inter-disciplinary space for collaborative engagement, and have used it primarily when articulating my conception of 'the digital humanities' as a field of study and intellectual activity. Hence it is also useful in depicting the collaborative domain of cross-disciplinary research projects, whose initiation and development require just such engagement.

The engagement begins with conversation, usually across disciplinary divides, in some cases across a number of such divides. If the conversations gain substance, they lead to more intensive interaction that will focus on the challenges a research collaboration would involve, related to source materials, research questions and research methods. If these challenges can be successfully negotiated and resolved, this will provide the basis for collaborative research which may well require and lead to innovation, very 
possibly in methods and perhaps techniques and tools, and will certainly lead to the creation of new knowledge.

It is a space where process is more important than product, and where method has primacy over techniques and tools. If all goes well, of course, the outcomes will include valuable and in many cases highly innovative products, and there will be significant use and possibly development of techniques and tools. It is important at the outset, however, to focus on the intellectual challenges, from which everything else follows.

This collaborative space may be virtual; some but not all scholars have an institutional structure-lab, centre, or department—specifically tasked to support digital humanities work.

There is now an extensive literature exploring this collaborative space and articulating the challenges and opportunities it encompasses. In Collaborative Research in the Digital Humanities edited by Marilyn Deegan and Willard McCarty, most of the chapters are devoted to this topic, including the INKE chapter by Ray Siemens et al. which I referred to above. $\frac{13}{13}$ Laszlo Hunyadi and Melissa Terras discuss collaboration between computer scientists, engineers, and humanists. In "Being the Other," Melissa Terras suggests thinking about the "distance" between the collaborating partners as a tool to understand the challenges in the collaboration. Laszlo Hunyadi, in "Collaboration in Virtual Space in the Digital Humanities," also offers valuable insights into collaboration involving scientists, engineers, and humanities scholars. In “No Job for Techies," John Bradley focuses on the dynamics of collaboration. Finally, Julia Flanders focuses on the challenges in relation to standards in "Collaboration and Dissent." In his interview with Charlotte Tupman in the same volume, John Unsworth begins with an articulation of what prompts digital humanities collaborations:

I think most collaborative projects take that form because they are trying to address a problem that requires a range of expertise that is not found in a single person, or because the scale of what is being undertaken is more than one person can do in a reasonable period of time, or both. They open up the possibility of doing interdisciplinary and multidisciplinary research, and tackle problems that do not fall neatly into disciplinary divisions of knowledge (Unsworth and Tupman, 231). $\frac{14}{}$

There is a great deal of valuable expertise beyond that single volume, of course. Jennifer Edmond's chapter "Collaboration and Infrastructure" in The New Companion 
to Digital Humanities is an important contribution, and her extensive bibliography is a good starting point for anyone interested in pursuing the literature further. She draws on Roberto Busa to describe "the digital humanities ideal: cutting-edge technological development and deep analog scholarly knowledge challenging each others' paradigms, facilitating each others' work, and validating each others' results" (Edmonds 55). This resonates with McCarty in Humanities Computing: "The overall conclusion from years of experience ... is that the tension between scholar and humanities computing practitioner, both alert to different things, is essential and creative." (127); and with Bradley in "No Job for Techies: Technical Contributions to Research in the Digital Humanities": "The development work-the application of the technology to humanities materials-is challenging, and requires intensive interchange of ideas in both directions" (22). Lynne Siemens has also published extensively in this area, e.g. "Alone, Further Together:' Reflections on INKE's Year Six" by Siemens and the INKE Research Group. $\underline{15}$

\section{The Collaborative Domain: Digital Humanities Specialists}

In my conception, there is an important role for those of us who take a particular interest in the collaborative space itself, and perhaps spend their careers working there, as I-and of course many others-have done, and who are concerned to understand what happens within the space. Often we provide the bridge between what in the diagram Willard and I think of as "the clouds of knowing" and the arts and humanities disciplines - the domains of application, as McCarty describes them-from where the source materials and the initial research questions may come (McCarty, Humanities Computing 118). Since technological changes and the new methods made possible by these changes occur so rapidly, I foresee a continuing role for a group that specialises in the space and in some important sense sees the need to take intellectual responsibility for it.

The most significant aspect of the space for collaborative engagement is that it fosters partnerships between specialists with different and complementary areas of expertise. Experience in the case study projects and in many other large projects world-wide suggests that even the "digital humanities specialist" category is likely to require more than one specialist, since a typical project of this kind will involve a number of different technologies. $\underline{16}$

I have spent time on this point because for the purposes of this paper the collaborative engagements discussed assume that the collaborating partners include at least one "digital humanities specialist" of the kind described above. This holds true for all the 
case studies. At the same time, I should emphasize that it is a convenient shorthand: there are many other models for successful engagements, those involving computer scientists for example. $\frac{17}{17}$ Since the case studies, however, were all based on the involvement of digital humanities specialists at King's, it makes the discussion more straightforward to continue it on that basis. The principles involved are likely to apply in more or less any configuration of collaborative partnership.

For convenience, I will distinguish between "application domain specialists" (ADS) from the "application domain"-e.g., literature, history, music, art history and so onand "technical research specialists" (TRS) from the "technical research domain"-i.e. the digital humanities specialists in each of the case studies.

\section{Section 4 : The Six Phases of Intellectual Development of Collaborative Projects}

\subsection{Objects of study and research questions}

The early conversations in the collaborative engagement space are likely to revolve around objects of study and the research questions to which they give rise. The TRS need to spend a good deal of focused time exploring these with their potential collaborators.

At the same time the ADS need to understand how different technical methods and approaches may be relevant to them. Depending on how familiar they are with advanced technical methods, some time may be required to help them understand some of the possibilities and their implications. At some point as the conversations develop, techniques such as rapid prototyping may be helpful, but at this early stage it can be beneficial for the entire team (both the ADS and the TRS) to explore other projects, including those with similar (or even different) objects of study or research objectives, and to consider how other scholars and research teams have approached similar challenges. The ADS will benefit from having a knowledgeable guide in the exploration of how different technical methods have been applied in different contexts, while the TRS will come to a better understanding of the objects of study.

These initial conversations may of course take many forms. Among the case studies, the IAph ADS initiated the conversations with a clear idea already in mind of how she wanted to proceed, being already familiar with some key projects and resources in Classics, including the Perseus Project, and the Thesaurus Linguae Graecae. She was also familiar with Elliott's and Cayless' work towards developing EPIDOC, the TEI 
standard for inscriptions. Since the TRS team included people with Classical training, it was possible for the initial conversations to proceed quite quickly.

The ADS for the FRH3 project, on the other hand, had little or no previous familiarity with technical methods nor with projects in related fields. Similarly, no one in the TRS team had a medieval English history background. Consequently, the initial phase of conversations took several months, with the ADS guiding the TRS through the complexities of their source materials-the manuscripts held in the National Archivesas well as providing a valuable critique of comparable print editions of similar manuscripts. Alongside this, the TRS were able to investigate other digital projects in medieval history for possible insights or ideas. One particularly relevant project was The Parliament Rolls of Medieval England, 1275-1504 (Given-Wilson et al, 2005), The TRS were also able to show the ADS team features of a range of projects that might be relevant in interesting ways, including not only from historical studies but also other fields, such as literature, art history and music. $\underline{18}$

\subsection{Research Objectives}

If there is a meeting of minds in the early part of the conversation, a natural development is to identify and agree the research objectives of the partnership. It is likely that the ADS will have broad aims in mind from the outset, but as the conversation proceeds it starts to become possible and useful to explore objectives at a more detailed level.

In PASE, the teams had detailed discussions around the written sources to be used, the types of information that could-and then should-be recorded for each person, and the types of retrieval and manipulation the completed resource should offer to future users. In CCEDB the partners looked in greater detail at the types of source document that would provide the data for the project and explored possible ways the data might be manipulated.

The intention at this stage of the process is not necessarily to define the research objectives in fine detail, but rather to explore them to a sufficient level of detail that informed decisions can be made about whether and how to take the research partnership forward.

The key requirement is for all partners to be as open-minded as possible from the outset, so that the problem space becomes a shared one, which each can come to see through the eyes of the other. As the dialogue develops the ADS gain new perspectives on their objects of study and the ways in which these may be interrogated, while the 
TRS can assess a range of possible technical approaches based on the objects to be studied and the research questions to be pursued--rather than relying on preconceived ideas about what kinds of technical approaches are 'best' for particular types of source materials. $\underline{19}$

It would be hard to over-state the importance of these initial conversations and interactions. They establish the intellectual basis of the research partnership if there is to be one, and provide an informed rationale for deciding not to proceed if that is the decision. For this reason it is worth investing as much time and attention to these conversations as may be needed. $\underline{20}$

\subsection{Project Proposals}

At this point, project teams often develop the project proposal needed to gain funding for the research. It is imperative that this task is tackled jointly on the basis of the collaborative framework the project team is working to establish. It is sensible for the ADS to take responsibility for initial drafting of the sections that relate directly to the objects of study and research objectives and the TRS for those elements that relate most directly to the technical research. In the end, however, it needs to be a collaborative effort, both as an expression of the research partnership already in process and a documented commitment to the future partnership if funding is obtained. $\underline{21}$

\subsection{Methods \& Mutual Education}

Depending on the partners, the nature of the planned research and other circumstances, this may be part of the conversation phase or the first part of the design and development phase. In either case it involves giving serious and detailed attention to the methods that are likely to be most useful in carrying forward the research, identifying whether existing methods are appropriate or need to be modified, or whether new methods are required.

For the IAph project, all partners quite quickly agreed that a 'standard' text mark-up approach would be best from a technical point of view, so the main innovations were working with Tom Elliot and Hugh Cayless as they developed the new EPIDOC standard for TEI, and modifying the XML-based publication platform under development in DDH. $\underline{22}$

At the same time while wishing to work as far as possible within the 'traditional' methods of epigraphical research, the ADS recognized that developments in 
methodology were needed in order to take advantage of the new opportunities afforded by digital editions, and took the view that these developments would be most effective if based on international collaboration between scholars; hence the commitment to at least three workshops per year, discussed in Section 2.

For the PASE project, the partners agreed at a reasonably early stage that the database framework developed for the Prosopography of the Byzantine Empire-based on what was described as a "factoid" approach-would provide a starting point for the key technical methodology, with adaptation to meet the different challenges posed by the source documents available for Anglo-Saxon England. $\underline{23}, \underline{24}$ The ADS meanwhile considered such matters as what editions/versions of the source documents would be used.

In the CCEDB project, the key challenges to both historical and technical methods lay in the disparate nature of the evidence and the wide dispersal of the repositories in which the materials were held. It was helpful that most of the evidence existed in a relatively small number of document types, each type following a reasonably standard format. This made it possible to create a small number of rather simple "data capture" databases, one for each document type. These were used by 'lightly trained' research volunteers-typically postgraduates, retired history teachers, and others interested in local history-who spent time in their local repository recording the key data. The completed "data capture" files were transmitted to the central ADS team, for editorial checking and uploading into a central database. This in turn was the basis for editorial work involving the ADS Principals, and in due course provided the backbone of the online publication. $\underline{25}$

It is worth emphasizing how much mutual education may be needed in this phase of the collaboration. For both the PASE and CCEDB projects, the TRS ran a series of workshops to explain the basic principles of information analysis and database design, while the ADS spent considerable time instructing the TRS in the complex range of source materials in question and the research challenges they were anticipating. So while this mutual education process most usefully begins during the initial conversation stage, it needs to be more intensive during each succeeding phase. In all the case studies, the mutual education took place over a number of months, which is typical of large projects. As noted above, the hugely collaborative INKE project started with six years of conversation and mutual education (Ray Siemens et al, 179).

In his paper "Collaborative Research in the Digital Humanities," McCarty notes that the domain specialists' research question may change at this point, saying that: 
A crucial part of the mind-change occurs through the non-technical scholar becoming grounded in digital methods, as a result of which he or she is able to understand in detail what the translation of a research question into digital language means. This grounding renders the non-technical scholar fit to participate in the design of whatever tool or resource is the object of the exercise. Participation often changes the initial research questions (4-5).

During this phase the ADS in the CCEDB project arranged to visit each of the over 50 repositories in which their source materials were housed. This had the dual benefit of gaining the direct-and enthusiastic-engagement of the archivist in each repository and also of ensuring that the ADS Principals obtained a very clear understanding of the types of document and the numbers of each type in each repository. This took place over the course of a whole year prior to the submission of the funding proposal, so that all the details of the planned approaches, along with the numbers and types of source documents involved, could be included in the proposal document - thereby giving the proposal more authority than it could otherwise have had.

\subsection{Analysis and Design}

In the context of the more or less complex, iterative and integrative processes under discussion, the labels attached to phases are illustrative and descriptive. In practice, the phases are likely to overlap a great deal and may in fact be completely inter-woven.

The collaborative dynamic becomes more intense in this phase and intellectual engagement deepens: difficult problems must be identified, the limits of intersection tested, and the required compromises fully explored. In any significant research project of this kind, it is absolutely certain that there will be uncomfortable challenges: this is inevitable when-to mis-quote and adapt from conversations with Willard McCarty-the rich imprecision of cultural expression meets the hard-edged rigidity of computational process. Talking about text markup, Julia Flanders expresses a similar sentiment:

Text markup of this kind, as practiced in the digital humanities world, sits at the juncture of humanities scholarship - textually nuanced, exploratory, and introspective - and digital technology with its emphasis on formalism, consistency and upward scalability (Flanders, 68). $\underline{26}$

The good news is that unless the objects of study are truly unique, other projects will have encountered the same challenges, so there will be models of possible ways to tackle them. The objects of study, however, will almost certainly have unique 
characteristics, so a certain amount of adaptation is likely to be required, but it is rarely the case that none of the existing models provides an appropriate way forward.

By this point the TRS need to have sufficient understanding of and familiarity with the objects of study that they can begin to design computational approaches with some degree of confidence. This will allow the TRS to produce a model of a possible technical structure or encoding system. This can then be shared with the ADS, and the implications and outcomes discussed. This is a highly iterative process, likely to produce a sequence of models until there is mutual confidence that a detailed design based on the final model will achieve the goals of the project. The iterative nature of this process is absolutely essential if the final design principles are to be clearly articulated, and clearly understood by all the partners. Not surprisingly this phase goes better the more time has been spent on mutual education.

The ADS' conception of their research objectives and questions may already have started to change through the conversations thus far, and it is possible and even likely that they will change further during the analysis and design, as new possibilities are imagined and explored. In addition, beyond the research that is the project's primary goal, there are research questions that the ADS know they will want to use the new system to help them address, research they can imagine other scholars will wish to pursue, questions that will be posed by students at all levels, and (what is increasingly important) questions of interest to a much wider public.

It is important to understand that at this stage the design is conceptual rather than practical. It is a crucial part of the collaborative engagement, intimate, intensive and highly iterative. It should be seen as the intellectual core of the work: the design that emerges from the analytical and modelling process will provide the platform and framework for all the work that follows, by both ADS and TRS. No model will be perfect, but a "good" one will be appropriate both in relation to the objects of study and to the research questions it will enable. $\frac{27}{2}$

Consequently this is the phase of work when a number of fundamentally significant decisions are taken which will determine the character of the research and its outcomes. In the CCEDB project, for example, it was the analysis of the source materials and their disparate locations that led to the design concept of having small single-target databases for data capture and a larger composite master database for editorial work and later publication. With the PASE project, on the other hand, an important element in the analysis was identifying the range of personal information that was available, and then deciding which would be the most important and useful to 
capture in a systematic way, taking into account both the availability (or sparsity) of the data and the subsequent research requirements.

All the case studies faced issues that are likely to occur early and often in this modelling process - those associated with categorisation. This is one of the oldest of scholarly practices of course, and is likely to be contentious to some degree in any research context. The difficulties are that much sharper when the categories have to be so precisely defined that they are reliably computable. ADS need to understand that if systematic (structured) searching and clear, consistent indexing are to be made possible, the categories must be carefully and precisely defined and the vocabularies to be used carefully specified - and 'controlled' in the system when it is constructed.

In FRH3 there were numerous issues around categorisation. One such was a classification scheme for types of fine, which was required to aid retrieval and analysis. The more contentious issues, however, were the conventions to be adopted for naming people and places. These are of course the types of question that arise in any scholarly work on material of this period and type; similarly the question of how best to represent dates is perennial. $\underline{28}$

Because these issues are so common, there are almost always tried and tested examples to follow. It is not completely unusual, however, to find that several different approaches have been adopted across a set of similar projects, so robust debate is still required to decide which of the conventions is a best fit. That said, the nature of the source materials or the research questions may require a new approach. It is crucially important in either case to document the chosen solutions and the underlying scholarly reasoning behind each choice-and then to apply these solutions consistently across the project!

It is worth emphasizing that the analysis and design phase continues to make extensive use of previous or current work. The PASE model as it emerged owed a great deal to other prosopographical projects in which DDH was also involved (in particular the Prosopography of the Byzantine World). $\underline{29}$ For FRH3 the printed 'calendars' of similar documents were an important point of reference, as were a number of other medieval projects, handling both documentary and nondocumentary sources of evidence.

The culmination of this phase of work is a set of documents formally expressing the basis of the collaboration, including its design principles, the importance of which cannot be over-emphasized (Ray Siemens et al. 181). As Flanders argues, negotiation 
and agreement on how the source materials will be encoded and manipulated represent the fundamental nature of the project collaboration. It is the negotiated design framework that serves the scholarship, owing its existence and effectiveness both to the intellectual and the practical collaboration between the research partners. With respect to sophisticated TEI structures, she suggests that the technical design "is not the appropriate mechanism for producing a successful collaborative agreement [but] is, rather, an extraordinarily effective mechanism for representing it" (Flanders 79). It was certainly the case that the formal design documents could be seen as representing the basis of collaboration in the case study projects, e.g. the EntityAttribute-Relationship diagrams in the case of PASE (and other projects using relational databases).

It is now standard practice to have created a project charter by this point in a project. In "The iterative design of a project charter for interdisciplinary research," Stan Ruecker and Milena Radzikowska explain that "the charter is based on the need to explicitly discuss principles and policies of research practice with people from different disciplines at the start of the project, and to have a common agreement to refer to if necessary during the project" (Ruecker and Radzikowska 1). There are a number of publications offering guidance and templates; for a preliminary list see Lynne Siemens' "Project Charters/Research Agreements Bibliography” (lynnesiemens.files.wordpress.com/2014/07/project-charters-bibliography.pdf).

\subsection{Project Progress, Review and Outreach}

The collaborative dynamic, once established, needs to be carefully nurtured and maintained throughout the project's life. It is certain that difficulties of various kinds will arise as the work progresses, and the response to these challenges needs to be collaborative in order to be effective. This is where well established principles of project management come to the fore, such as careful documentation of work done, regular team meetings, setting of both short- and longer-term objectives, and so on. Good project management pays off in numerous ways, not least in making it possible to anticipate problems and plan for them. If it becomes clear, for example, that some part of the promised outcomes will not be achieved, it is important to communicate this to funders, advisory boards and project supporters as early as possible. Early communication is more likely to get a positive response, both to the problems and to the proposed solutions.

As indicated at the outset, these aspects of managing the projects are not given specific attention in this paper, but they are extremely important, and there is a large 
and ever-growing literature on the subject. As mentioned above, Lynne Siemens has published widely on these and other aspects of project development and management (note in particular Siemens, "More Hands" and "Project Management"). In addition she offers a one-week course at the annual Digital Humanities Summer Institute in Victoria, Canada: Introduction to Project Planning and Management for DH: Issues and Approaches (dhsi.org/course-offerings/). The course entry on the website provides a link to course materials from previous years, including a great deal of useful guidance and support materials. For a useful checklist, see also Bethany Nowviskie, "Ten rules for humanities scholars new to project management".

Generally speaking projects can benefit hugely from a group of expert "friends". It was, for example, the norm in the case studies (and in large collaborative projects at King's generally) to establish an International Advisory Group. $\underline{30}$ In many cases this was recruited during the preparation of the funding proposal so it could be named in the submission. There would be regular email contact with the IAG, but also annual meetings, at which the project team would report on the completed, current and planned work, and on issues needing resolution. This process ensured regular specialist review of the project, and in many cases the external expert advice was of great help in addressing difficulties that had arisen. In the FRH3 project, for example, the IAG were very actively engaged in discussions about the conventions to be adopted, such as those for person and place names and categories of fine.

Projects also benefit from regular exposure to a wider audience, of scholars and also the wider public. PASE was one of the projects that arranged a one-day conference to follow each year's IAG meeting. These conferences included presentations by the research teams showing how the domain and technical work was interwoven, and also invited presentations from a wide range of scholars likely to have experience and insights from which the project would benefit. This included not only medieval historians, but specialists in Anglo-Saxon literature, archaeology, epigraphy, onomastics, and numismatics.

Reference was made earlier to the central role in IAph of specialist workshops, whose aim was to engage as widely as possible with scholars interested in "small chunks" of source materials. Each workshop had a theme such as prosopography, iconography, papyrology, classical history, and so on. This approach had two key objectives: to invite this wide group of scholars to contribute their perspectives to the work of the project and, if possible, to gain their commitment to the community-wide development of 
standards and approaches that could be used across many different geographical and disciplinary areas.

FRH3 not only had a very active and supportive IAG, but for the second phase of the project also appointed a Knowledge Transfer Advisory Group to offer guidance on how best to engage with the wider public. This group comprised teachers, broadcasters, journalists, curators and county archivists. One example of outreach activity initiated by this group was an exhibition at the Norfolk County Archives of their range of $13^{\text {th }}$ Century holdings, with information and guidance on the project and a number of terminals linked to the project website.

FRH3 also initiated a Fine of the Month feature, each month publishing on the website a new article discussing some aspect of a fine or a group of fines. The early articles were written by members of the ADS team or the IAG, but once the first set of fines became available online, within about 9 months of the project start (with "health warnings" about this being work in progress) all readers were invited to submit articles for publication as a Fine of the Month. Indeed a bottle of champagne was awarded each year to the "outsider" judged to have produced the most interesting article. With the help of these "outsiders," 84 articles were created by the close of the project. These articles were useful both in engaging the public and in providing examples of how the project materials could be used in research.

It is usual through the life of a project that both ADS and TRS, sometimes jointly, will present papers at conferences or publish articles. This is another important form of peer review and outreach. INKE is a good example of a well-documented collaborative digital humanities project.

Regular exposure to the wider communities has a number of benefits for a project. It invites comment, creates space for rigorous scholarly criticism, leads to new information, and ensures active engagement with the communities it seeks to benefit. $\underline{31}$

\subsection{The Unexpected}

Every large project encounters unexpected challenges. These may be to do with source materials, or the progress of the domain research, or the technical research and development, or any combination of these. They may arise from the project work or from personal difficulties faced by project team members. Whatever the challenges, and whatever strategies are adopted to deal with them, the quality of the initial work 
and the soundness of the collaborative relationship between the partners will be critical in responding to them.

Perhaps the most common challenge is to do with timescales, especially in large multiyear projects. However careful the initial and ongoing planning may be, both the ADS and TRS teams may find it is taking longer to achieve certain work than anticipated.

The case study project least affected by this was IAph, whose source materials were well known in advance, and which had a prior project as the basis for the technical work. As previously mentioned, the source texts for phase 1 of PASE had also been identified in the first phase of the project. But, as Nelson explains in "From Building Site to Building," the introduction of the Domesday Book mataerials posed a huge challenge to PASE because it was so different from the other source material (Nelson 128-129).

For FRH3 the major challenge came with the realisation during the final two years of the project that in the remaining time available it would be impossible to complete mark-up for all the remaining rolls (1249-1272) to the desired standard. After much anguished deliberation, the project decided (with the full backing of the IAG and the funding body) to reduce the degree of mark-up in the final sequence of rolls in order to ensure that the complete text of Henry III's Fine Rolls was translated and available. As a result, the translation was completed for the entire period (1216-1272). For the rolls in the period 1216-1248, there are Person, Place and Subject indexes, making it possible to carry out structured searches. For rolls in the period 1249-1272 readers have the translation and can use free text searches. Everyone involved would have preferred to avoid this compromise, but over the ensuing years it has not been a source of complaint, and the publication is extensively used for what it does offer.

In the CCEDB project, the first research fellow responsible for checking and uploading the data collection databases encountered personal difficulties, which resulted in much slower and less reliable progress than planned. This posed a major challenge to (and put additional pressure on) the three principal researchers because they had to undertake checking and uploading while they recruited a new research fellow to replace the first.

For the TRS, the big challenge came later in the project when the ADS undertook the complex task of modelling a clerical "career." This involved linking a "person" to a set of documents starting with ordination and moving temporally through that person's clerical appointments. Provisional identification was performed as individuals were 
uploaded into the main database, but the additional steps required to manually link records was extremely time-consuming. In response to this issue, the TRS worked with the ADS to identify a set of rules which would allow the TRS to further automate the process by linking records. This created a provisional "career" for each person, which the ADS could then check and edit, speeding up the process considerably.

CCEDB also illustrates another serious but common challenge to a project's completion. As the work proceeds, and especially if it is going well, new questions and new possibilities present themselves-an example of scope creep. There is merit in modifying the project's scope: it is less costly than starting a new project later to answer these questions. But if the project is drawn into too many 'new directions', the primary objectives can be put at risk. A balance has to be reached, typically some kind of compromise; here again the quality and depth of the collaborative relationship is of crucial importance.

\section{Section 5: Conclusions}

In this paper I have tried to show the importance for a project's success of a deep intellectual engagement between the project partners, working as equals across discipline boundaries. This begins with the initial conversations around research objectives and the source materials, deepens through the process of mutual education by the ADS and the TRS, and continues through the collaborative analysis and design phase. In the kinds of project under discussion, this analysis and design is very likely to be formal and highly structured, so will generally be led by the TRS; the full intellectual engagement in the process by the ADS is, however, vital.

Application of practical project management techniques is equally necessary. This includes documentation of design decisions, project planning, and formal agreement on roles, responsibilities and credits (a "project charter"). All this together constitutes a solid collaborative framework which will prove invaluable in navigating the development of the project, and addressing unexpected challenges. Technology plays a crucial role, but it is the early and continuing intellectual engagement by all the project partners which ensures the long-term success of a project.

Finally, there are many important topics given little attention in this paper, which is not to downplay their significance. Two of these are the issues of long-term maintenance (both intellectial and technical) and preservation. Many current large collaborative projects involve librarians and archivists from the outset. This is encouraging not only because they bring invaluable subject expertise, but also because it ensures that 
planning and preparation for the post-publication future is an integral part of the project development from the very beginning. $\underline{32}$

\section{Appendix A: Checklist}

For reference, the paper ends with a summary checklist of the phases and recommendations discussed:

\section{General Recommendations}

- Build a collaborative relationship between the ADS and the TRS through crossdisciplinary conversation.

- Maintain collaborative relationship throughout the project, including when addressing unexpected challenges and difficulties (e.g., scope creep, funding issues).

- Aim for compromises that satisfy the entire project team.

- Define a robust set of relevant project management practices (formal documentation).

- Bonus: prepare for long-term preservation and maintenance by involve librarians and archivists from the outset.

\section{Phases of Intellectual Development}

- Phase 1: Focus on objects of study and research questions.

- Phase 2: Determine research objectives.

- Phase 3: Write a collaborative project proposal.

- Phase 4: Define methods and provide mutual education.

- Phase 5: Complete collaborative analysis and design (formal documentation.

- Phase 6: Develop a review and outreach strategy that incorporates expert "friends", workshops, conferences, and publications

\section{Appendix B: Projects Cited 33}

\section{Case Study Projects $\underline{34}$}

Arthur Burns, et al. CCEd: The Clergy of the Church of England Database 1540-1835. King's College London, 2005, https://theclergydatabase.org.uk/. 
David Carpenter, et al. Henry III Fine Rolls Project. The National Archives and King's College London, 2009, https://frh3.org.uk/index.html.

Charlotte Roueché et al. Inscriptions of Aphrodisias (IAph2007). King's College London, 2007, http://insaph.kcl.ac.uk/iaph2007/index.html.

Charlotte Roueché. Aphrodisias in Late Antiquity, https://insaph.kcl.ac.uk/ala2004.

Stephen Baxter, et al. Prosopography of Anglo-Saxon England: Home. King's College London, 2010, https://pase.ac.uk/.

\section{Other Projects}

AHRC ICT Methods Network, methodsnetwork.ac.uk.

CLARIAH: Common Lab Research Infrastructure for the Arts and Humanities, www.clariah.nl/en.

CLARIN: European Research Infrastructure for Language Resources and Technology, www.clarin.eu.

Collective Biographies of Women, womensbios.lib.virginia.edu.

DARIAH: Digital Research Infrastructure for the Arts and Humanities, www.dariah.eu.

Emily Dickinson Archive, www.edickinson.org.

EPIDOC, sourceforge.net/p/epidoc/wiki/Home.

GODOT: Graph of Dated Objects and Texts, godot.date/home.

HuNI: Humanities Networked Infrastructure, huni.net.au.

INKE: Implementing New Knowledge Environment, inke.ca.

Perseus Project, www.perseus.tufts.edu.

Pleiades. pleiades.stoa.org.

Prosopography of the Byzantine World, pbw2016.kdl.kcl.ac.uk.

Rossetti Archive, www.rossettiarchive.org.

TEI: Text Encoding Initiative, tei-c.org. 
Thesaurus Linguae Graecae, stephanus.tlg.uci.edu.

The Valley Project, valley.lib.virginia.edu.

Walt Whitman Archive, whitmanarchive.org.

William Blake Archive, www.blakearchive.org.

\section{Works Cited}

Bradley, John, “No Job for Techies: Technical Contributions to Research in the Digital Humanities". Collaborative Research in the Digital Humanities, edited by Marilyn Deegan and Willard McCarty, 2012, pp. 11-25.

Bradley, John and Harold Short. "Texts into Databases: The Evolving Field of New-style Prosopography”. Literary and Linguistic Computing, vol. 20, Suppl. no 1, Jan 2005, pp. 3-24, doi.org/10.1093/llc/fqi022.

Collaborative Research in the Digital Humanities, edited by Marilyn Deegan and Willard McCarty, 2012, doi.org/10.4324/9781315572659.

Digital Research in the Arts and Humanities, Routledge, Taylor \& Francis Group, www.routledge.com/Digital-Research-in-the-Arts-and-Humanities/bookseries/DRAH.

Edmond, Jennifer. "Collaboration and Infrastructure". A New Companion to Digital Humanities, edited by Susan Schreibman, et al., John Wiley \& Sons Ltd, 2015, 5465. doi.org/10.1002/9781118680605.ch4.

Flanders, Julia. "Collaboration and Dissent: Challenges of Collaborative Standards for Digital Humanities". Collaborative Research in the Digital Humanities, edited by Marilyn Deegan and Willard McCarty, Ashgate Publishing Limited, 2012, pp. 67-80.

Given-Wilson, Chris. The Parliament Rolls of Medieval England, 1275-1504. Edited by C. Given-Wilson, A. Curry, R. Horrox, G. Martin, S. Philips, \& M. Ormrod. 16 vols. + CDROM. Woodbridge: Boydell Press; London: National Archives, 2005. On DVD and online at www.sd-editions.com/PROME/. 
Hunyadi, László. “Collaboration in Virtual Space in the Digital Humanities". Collaborative Research in the Digital Humanities, edited by Marilyn Deegan and Willard McCarty, 2012, pp. 93-103. doi.org/10.4324/9781315572659.

Mapp, Rennie. “Enterprise Architecture as a Framework for Digital Humanities Project Administration", Project Management in the Humanities hosted by Digital Humanities Summer Institute, 2020 Victoria, BC, Canada.

McCarty, Willard. Humanities Computing. Palgrave MacMillan, 2005.

--. "Collaborative Research in the Digital Humanities". Collaborative Research in the Digital Humanities, edited by Marilyn Deegan and Willard McCarty, 2012, pp. 1-10.

Nelson, Janet L, “From Building Site to Building: The Prosopraphy of Anglo-Saxon England (PASE) Project”. Collaborative Research in the Digital Humanities, edited by Marilyn Deegan and Willard McCarty, 2012, pp. 123-134.

Nowviskie, Bethany. "Ten rules for humanities scholars new to project management". DH Handouts, 2012, nowviskie.org/handouts/DH/10rules.pdf.

Roueché, Charlotte. "Aphrodisias in Late Antiquity”. Journal of Roman Studies, Monograph 5, 1989, pp. 299-300. https://doi.org/10.2307/301351.

Ruecker, Stan, and Milena Radzikowska. "The Iterative Design of a Project Charter for Interdisciplinary Research". DIS '08: Proceedings of the 7th ACM Conference on Designing Interactive Systems, ACM Press, February 2008, pp. 288294. doi.org $/ 10.1145 / 1394445.1394476$.

Short, Harold et al. "'Collaboration must be fundamental or it's not going to work': An Oral History Conversation between Harold Short and Julianne Nyhan”. DHQ: Digital Humanities Quarterly, vol. 6, no.

3, 2012, digitalhumanities.org/dhq/vol/6/3/000133/000133.html.

Siemens, Lynne. Issues in Large Project Planning and Management. Digital Humanities Summer Institute 2012, Harry Hickman Building, Room 120, University of Victoria. dhsi.org/wp-content/uploads/2019/09/12.ProjectPlanning.pdf.

---. “'More Hands' Means 'More Ideas': Collaboration in the Humanities”. Humanities, vol. 4, no. 4, Aug 2015, pp. 353-368, www.mdpi.com/2076-0787/4/3/353. 
---. "Project Management and the Digital Humanist". Doing Digital Humanities

Practice, Training, Research, edited by Constance Crompton, Richard J. Lane, and Ray Siemens, Routledge, 2016, pp. 343-357.

Siemens, Lynne and INKE Research Group. “'Faster Alone, Further Together':

Reflections on INKE's Year Six”. Scholarly and Research Communication, vol. 7, no. 2, Nov. 2016, doi.org/10.22230/src.2016v7n2/3a250.

Siemens, Ray et al. "Human-Computer Interface/Interaction and the Book: A Consultation-Derived Perspective on Foundational E-Book Research". Collaborative Research in the Digital Humanities, edited by Marilyn Deegan and Willard McCarty, 2012, pp. 163-189.

Smithies, James. "A View from IT”. Digital Humanities Quarterly, vol. 5, no. 3, June 2011, www.digitalhumanities.org/dhq/vol/5/3/000107/000107.html.

Smithies, James et al. "Managing 100 Digital Humanities Projects: Digital Scholarship \& Archiving in King's Digital Lab”.DHQ: Digital Humanities Quarterly, vol 13, no. 1, Apr 2019, digitalhumanities.org/dhq/vol/13/1/000411/000411.html.

Terras, Melissa. "Being the Other: Interdisciplinary Work in Computational Science and the Humanities". Collaborative Research in the Digital Humanities, edited by Marilyn Deegan and Willard McCarty, 2012, pp. 213-230.

Unsworth, John. “Creating Digital Resources: The Work of Many Hands”. Delivered at the Digital Resources in the Humanitiesconference, Institute for Advanced Technology in the Humanities, England, 1997, johnunsworth.name/drh97.html.

Unsworth, John and Charlotte Tupman. "Interview with John Unsworth, April 2011, carried out and transcribed by Charlotte Tupman". Collaborative Research in the Digital Humanities, edited by Marilyn Deegan and Willard McCarty, 2012, pp. 231-239.

\section{Footnotes}

1. In three of the projects, PASE, FRH3 and IAph, I was also formally a CoInvestigator. $\subseteq$

2. For the URLs of these projects see "Projects Cited: Case Study Projects". A glance at their websites will show how widely collaborative these projects were and remain!

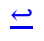


3. For the URLs of all the named projects see "Projects Cited: Other Projects". $\bullet$ 4. E.g. see Alison Booth's Collective Biographies of Women project at the University of Virginia (visited November 2020). $\subseteq$

5. Domesday Book is a uniquely valuable resource for historians of this period of English history. It is the country-wide survey of ownership and values ordered by William the Conqueror in 1086, 20 years after his invasion of England from Normandy in 1066.

6. Many such projects would have included transcription of the Latin originals, but the historians involved, including the International Advisory Group, took the view that medieval historians would be more than satisfied with high-quality digital facsimiles, so the project's precious resources could be devoted to English translation, thereby making the materials accessible to a wider readership. $\_$ 7. Some of these can be found in DDH's Completed Projects list, though this list is incomplete even for those that were based at King's. See: https://www.kcl.ac.uk/artshums/depts/ddh/research/projects/completed/index? GenericList_AtoZLetter $=\mathrm{I}$.

8. Roueché's principal collaborator was the Cambridge archaeologist Joyce Reynolds.

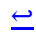

9. These inscriptions are texts inscribed in stone, almost all in ancient Greek. 10. This project was funded by a grant from the Leverhulme Trust. $\subseteq$ 11. EPIDOC is at the heart of thriving community of scholars. $\subseteq$ 12. This colloquium was an initiative of the Association for Literary and Linguistic Computing (ALLC), now the European Association for Digital Humanities (EADH eadh.org). Zampolli was ALLC President at the time.

13. This volume was a Festschrift for the author on my retirement and is published in the Ashgate/Routledge series Digital Research in the Arts and Humanities (see "Works Cited"). The series had its origins in the AHRC Methods Network project another highly collaborative undertaking; see "Projects Cited." To date over 35 volumes have been published in the series, with more in preparation. (Disclosure: the author is one of the Series Editors.) $\leftrightarrows$ 
14. In our experience at King's, we found that DDH was largely able to avoid territorial 'wars' precisely because the collaborative research was something that the humanities scholars could not do without DDH, and vice versa. Since the project funding was "new" money, it was not a drain on department finances; the whole enterprise benefited everyone, not only intellectually but also institutionally. $€$ 15. As the subtitle of this publication indicates, the essay is Lynne Siemens' reflections on Year 6 of the INKE project. She has previously published reflections on each of its first five years. Details of these and others of her papers on project collaboration can be found on the University of Victoria website at https://www.uvic.ca/hsd/publicadmin/people/home/faculty/siemens-lynne.php, or in the Research section of her personal website at https://lynnesiemens.wordpress.com/other-information. Details of the INKE papers can also be found on the INKE project website (see "Projects Cited"). 16. In each of the case studies, as well as many other projects at King's, it was common in applications to request somewhere between 0.5 and 1.0 full-time equivalent funding for the technical research, which would be used to provide smaller allocations of time from a number of analysts and developers within the department, each with a different technical specialism. $\leftrightarrows$

17. One important role of the digital humanities specialist(s) is to bridge the gap between the domain specialists and the technology, and those performing this role have been variously described using terms such "intermediaries" or "translators". (Edmond 57). Such a role is essential of course, but digital humanities specialists are also able to engage at deeper levels in the collaborative relationship. $\triangleq$ 18. It is in part the nature of the "methodological commons" that offers such opportunities. It is often illuminating for scholars to see commonalities and similarities in "foreign" disciplinary territory. $\triangleq$

19. It should be acknowledged that in some cases, especially where a compelling model is provided by an existing project regarded as successful, the TRS may be approached precisely because of particular technical expertise, and consequently there may be little doubt about the technical basis that will be used and adapted as appropriate. This has certainly been the case, for example, in the numerous 'small chunks of text' projects that have been based on the EPIDOC standard, and also in a number of prosopography projects in which DDH has been involved, following the models of the Prosopography of the Byzantine World and PASE. $\bullet$ 
20. This is widely asserted in the digital humanities literature, but note in particular the discussion in Ray Siemens et al. $\_$

21. In each of the case studies, the major funder was the UK's Arts and Humanities Research Council (AHRC) or its predecessor, the Arts and Humanities Research Board. At the time all applications required a Technical Appendix, setting out in some detail the planned technical research and development. DDH as the TRS therefore took responsibility for the initial drafting of this Appendix, while our partner ADS did the initial work on the main body of the proposal. Mutual review ensured that the submitted proposal was always truly joint. $\triangleq$

22. In fact, this was subsequently used, with modification where required to meet the needs of each new project, as a basis for the online publication of almost all major projects in which DDH was involved. $\bullet$

23. Further discussed in the Analysis and Design section below. $₫$

24. For a description and discussion of this approach, see John Bradley and Harold Short. This approach was first designed by Gordon Gallacher, but extended and further developed by John Bradley, who had a major technical research role in all the prosopography projects in which DDH was involved, and also in the CCEDB project, which has important prosopographical elements. $\boxminus$

25. The ideal approach would have been to digitise all the source documents, and use these as the basis for further processing. The costs of digitising and transcribing all the source documents would, however, have been prohibitive, so the three Principal ADS decided it would be preferable to do something as comprehensive as possible on the basis described, rather than collect a much smaller subset using the alternative approach. $\_$

26. Although not explicitly used in the Case Study projects, it is well worth reviewing formal analysis and design frameworks, which will provide many practical insights even if they are not formally adopted. Enterprise Architecture is an interesting over-arching framework that covers all aspects of project development and management. It was first proposed for the Digital Humanities by James Smithies in "A View from IT", and is explored by Rennie Mapp in her paper for the Project Management in the Humanities conference. $\_$

27. The subject of modeling in the digital humanities is an important one in the field. It has been a frequent concern for Willard McCarty, and was the subject of one of the 
chapters in Humanities Computing (20-72). $\triangleq$

28. It should be noted that new projects have many more resources to draw on today. A number of projects have been set up, often led by Classicists, to create 'universal' gazetteers of geographical locations and dates. The Pleiades project is one example of the former, while the GODOT project (Graph of Dated Objects and Texts) is an example of the latter. Although GODOT started with a focus on the ancient world, it has expanded. In November 2018 it organised a workshop on "NonGregorian Calendar Dates in Digital Humanities" in Heidelberg. (For project URLs, see "Projects Cited".) $ヒ$

29. At the time, this project's title was Prosopography of the Byzantine Empire, and its sources were primarily Greek and Latin. The name was changed subsequently when the scope of source material was broadened to include a wider range of languages and regions. (See "Projects Cited"). $\leftrightarrows$

30. "Advisory" rather than "Steering"! It's best all round for the Principal and CoInvestigators to have the primary responsibility for directing the project. $€$

31. FRH3, for example, received valuable feedback from local historians who were able to offer new information and corrections that improved material on the project website. As indicated earlier, CCEDB was supported by a large number of teachers, local historians and students, who gathered the initial data sets, and continued to provide feedback as the project progressed. The project was even named "resource of the month" by a United States genealogy society. $\_$

32. The King's Development Lab, led by James Smithies, is responsible for maintaining and preserving the Case Study projects. See Smithies et al 2019 for a wide-ranging discussion of maintenance issues, plus a useful bibliography. $\subseteq$

33. Project websites and URLs referenced below were all visited in May 2021.

34. Principal Investigators are named. For all other members of the research teams, including Co-Investigators, as well as other project details, see the project websites. $\subseteq$ 